\title{
A IMPORTÂNCIA DO IMAGINÁRIO SOCIAL PARA A CONSTRUÇÃO DAS PRÁTICAS DE ENSINO-APRENDIZAGEM CONTEMPORÂNEAS
}

\section{ARTIGO ORIGINAL}

PESSOA, Andréa Printes Nogueira ${ }^{1}$

NOGUEIRA, Francinete Pessoa ${ }^{2}$

NORONHA, Jucineide Campos ${ }^{3}$

PESSOA, Andréa Printes Nogueira. NOGUEIRA, Francinete Pessoa. NORONHA, Jucineide Campos. A importância do imaginário social para a construção das práticas de ensino-aprendizagem contemporâneas. Revista Científica Multidisciplinar Núcleo do Conhecimento. Ano 05, Ed. 10, Vol. 22, pp. 133-144. Outubro de 2020. ISSN: 2448-0959, Link de acesso: https://www.nucleodoconhecimento.com.br/educacao/imaginario-social

\section{RESUMO}

Este artigo traz reflexões sobre a importância do imaginário social, contextualizado a partir de pesquisas bibliográficas sobre o que é imaginário social e como funciona no ensino-aprendizagem contemporâneo. A aprendizagem, é um processo no qual

${ }^{1}$ Licenciada em Física; Corporacion Universitaria De Humanidades E Ciencias Sociales De Chile. Mestrado Em Ciências Da Educação.

2 Licenciada em matemática e Especialista no Ensino da Matemática e em Gestão e Coordenação Pedagógica e em Docência do Ensino Superior SEDUC; Corporacion Universitaria De Humanidades E Ciencias Sociales De Chile Mestrado Em Ciências Da Educação.

${ }^{3}$ Licenciada em letras e especialização em Metodologia do Ensino de Língua Portuguesa e Especialização em mídias na Educação; Corporacion Universitaria De Humanidades E Ciencias Sociales De Chile Mestrado Em Ciências Da Educação. 
desenvolvemos nossa personalidade, seja ela física ou mental. Nas escolas nas práticas de ensino aprendizagem contemporâneas, o professor, tem a função de sistematizar os conhecimentos dos alunos a partir da sua vida social, organizando as atividades, para preparar os alunos a seguirem as normas, valores, que são criados pela sociedade com significações e sentidos verdadeiros seja em grupo ou individual.

Palavras-chaves: Imaginário social, ensino-aprendizagem, mundo contemporâneo.

\section{INTRODUÇÃO}

Para analisar a importância do imaginário social no ensino-aprendizagem, destacamse as intensas transformações na educação contemporânea. O processo educacional passa por evolução em vários aspectos, principalmente nas metodologias de ensino, devido às modificações sociais continuas, como: o desenvolvimento tecnológico e as evoluções cientificas que exige melhorias no campo pedagógico, para facilitar esse processo e proporcionar bem-estar aos envolvidos.

Imaginário social: se expressa por ideologias e utopias, e também por símbolos, alegorias, rituais e mitos. Tais elementos plasmam visões de mundo e modelam condutas e estilos de vida, em movimentos contínuos ou descontínuos de preservação da ordem vigente ou de introdução de mudanças.

No Brasil, as instituições de ensino buscam desenvolver estratégias para aplicar na metodologia diária de maneira a envolver o ensino-aprendizagem alicerçado na convivência humana diante da vida familiar, na sociedade e no saber cultural de sua comunidade. Daí o papel da escola na sociedade moderna necessita de novas estratégias de ensino, de modo a responder às novas demandas econômicas e sociais, com práticas pedagógicas que implementam o uso das tecnologias disponíveis, nas aulas. 


\section{DESENVOLVIMENTO}

\subsection{A IMPORTÂNCIA DO IMAGINÁRIO SOCIAL}

Inicialmente, devemos compreender o que é imaginário. Então, para iniciar o estudo da temática proposta, buscou-se entender esse afastamento dos aparatos científicos e, de modo simplificado tem se a seguinte definição:

A atividade criadora da imaginação depende diretamente da riqueza e da diversidade da experiência anterior da pessoa, porque esta experiência constitui o material com que se criam as construções da fantasia. Quanto mais rica a experiência da pessoa, mais material está disponível para imaginação dela. (VYGOTSKI, 1996, p. 22)

Desta forma, fica explícita a relação do imaginário individual com o imaginário social, pois nota-se que muitas situações da realidade humana são complementadas por essa busca incessante de significados. Com tudo, a imaginação e a realidade são processos que viabilizam a atualização constante da vivência cotidiana e atuam nas dimensões da formação social.

Esse imaginário social é o agrupamento das normas e dos valores, criados pela sociedade com significações e sentidos verdadeiros. Nesse caso, o imaginário social ou coletivo precede da interação entre os membros de um determinado grupo. Isso acontece porque:

A imaginação adquire uma função muito importante no comportamento e no desenvolvimento humano. Ela transforma-se em meio de ampliação da experiência de um indivíduo porque, tendo por base a narração ou a descrição de outrem, ele pode imaginar o que não viu, o que não vivenciou diretamente em sua experiência pessoais. (VYGOTSKY, 1996, p. 125)

Vale ressaltar a necessidade de aproximar as significações aos processos de ensino e aprendizagem, que fomente o discurso para se compreender aquilo que está além das possibilidades humanas, com isso pode se trabalhar um sistema dinâmico e continuo. 
E em vista desse pensamento, se apropriar do imaginário, é trabalhar conceitos e representações nas diferentes áreas do conhecimento, tais como: antropologia, sociologia, história, dentre outras. Vários teóricos explicitam diferentes significados relacionado ao imaginário social. Postic (1993, p. 13) sugeri a seguinte reflexão:

Imaginar é uma atividade de reconstrução, até de transformação do real, em função dos significados que damos aos acontecimentos ou das repercussões interiores que eles têm em nós. Não é afastar-se em relação ao mundo real; é seguir ao mesmo tempo uma via paralela.

Diante das atividades que permeiam a transformação em função da relevância dos significados, Pesavento (1995, p. 24) enfatiza: "O imaginário é, pois, representação, evocação, simulação, sentido e significado, jogo de espelhos onde o "verdadeiro" e o aparente se mesclam, estranha composição onde a metade visível evoca qualquer coisa de ausente e difícil de perceber. Ainda sintetizando o pensamento do autor, perseverar o estudo do imaginário pode chegar a entender significados e desvendar segredos.

Nesse contexto, o importante é que o professor compreenda os sentidos, símbolos e significados do imaginário que contribuem com a educação e geram conhecimentos, propiciando as relações de ensino-aprendizagem, devido às práticas pedagógicas.

É na escola que se constrói a possibilidade de compreensão da realidade, partindo de uma proposta curricular que norteia os trabalhos em sala de aula, para posteriormente aplicar provas e avaliações, que geram resultados escolares. Assim se projeta e disponibiliza atividades, a partir dos interesses individuais, pois cada um tem uma realidade diferenciada e passa a construir coletivamente um instrumento humanizador. Fazendo analogia do imaginário em relação a pedagogia, detêm-se a afirmação que:

Imaginar é evocar seres, colocá-los em determinada situação, fazê-los viver como se quer. É criar um mundo a seu bel-prazer, libertando-se. Tudo é possível. Tudo acontece. Na vida artística, imaginar é um ato criador. Na vida cotidiana, imaginar é uma atividade paralela à ação que exercemos ligada à realidade. A imaginação é um processo. O imaginário é seu produto. Imaginário social e a educação: uma aproximação necessária. (POSTIC,1993, p.13) 
O imaginário fomenta práticas educacionais e levam os alunos a outra dimensão, o conhecimento dá significado à existência da instituição escolar. A escola é mediadora entre a cultura e o indivíduo, busca o desenvolvimento da inteligência criativa e permitem diferentes manifestações que possibilita a socialização do indivíduo, a educação movimenta imaginários e produz novos sentidos e significados. Destacado por (CASTORIADIS, 2004, p.129), "a sociedade age segundo o sentido que dá ao mundo e as coisas que a rodeiam [...] a linguagem, os costumes, as normas, as técnicas não podem 'ser explicadas' através de fatores exteriores a coletividade humana".

Dessa forma entende-se o imaginário como participante do cotidiano coletivo, como ideário de uma sociedade em busca de validar as situações no campo da política ou de outros grupos sociais, como também em campos das ciências. O imaginário social representa os anseios que as classes sociais expressam para nortear seus objetivos, suas ideologias, nos quais se apropriam da avaliação do passado para tornar o futuro mais autêntico pautado na valorização da estrutura social sobre o individual, pois a vida social permeia pela identificação significativa do conhecimento, dos valores e normas a partir de sistemas de representações simbólicas.

\subsection{A CONSTRUÇÃO DAS PRÁTICAS DE ENSINO-APRENDIZAGEM}

As ideias pedagógicas têm relevantes contribuições teóricas e vem ao longo dos anos alimentando o pensamento do público educacional. As práticas são recursos metodológicos que facilitam o processo de ensino-aprendizagem, relaciona teoria à prática e possibilita o desenvolvimento de questionamentos e desperta a curiosidade do aluno. Hoje é necessário buscar aperfeiçoamento do processo educativo, a escola já saiu teoricamente do ensino tradicional, e o professor se ver obrigado a estar por dentro das inovações, e se valer da criatividade e modernização na sala de aula, para satisfazer uma geração informatizada, no Brasil os PCNs foram organizados propondo novas práticas pedagógicas para minimizar os resultados diante das práticas tradicionais. Diante do exposto. 
Democratizar o ensino é ajudar os alunos a se expressarem bem, a se comunicarem de diversas formas, a desenvolverem o gosto pelo estudo, a dominarem o saber escolar; é ajudá-los na formação de sua personalidade social, na sua organização enquanto coletividade. (LIBÂNEO, 2006, p. 12)

Assim, se percebe que a evolução educacional perpassou por várias situações, desde à escola tradicional, escola moderna e hoje com significativa evolução na escola contemporânea, que com os avanços tecnológicos possibilitaram soluções rápidas para o ensino. Mas ensinar não depende só de tecnologias, o ensino aprendizagem é algo complexo onde podemos aprender ou deixar os ensinamentos em segundo plano, ou para mais tarde, tudo depende do interesse particular do indivíduo.

As escolas, independente da sua localização ou da clientela que atende, tem como princípio formar cidadãos conscientes, responsáveis com autonomia intelectual capazes de acompanhar as mudanças sociais que acontecem em ritmo cada vez mais acelerado. Nesse patamar, o professor precisa adquirir diferentes estratégias de ensino. Para Libâneo (2006, p. 78), "O professor precisa, portanto, de uma teoria que explicite a direção pretendida para a tarefa educativa de humanização do homem, extraída de uma concepção de educação enquanto prática social transformadora." De frente com essa necessidade, os métodos pedagógicos adotados pelos professores são importantes para que o ensino aprendizagem ocorra, fazendo associação da teoria com o seu cotidiano e o cotidiano do aluno; os saberes disciplinares do seu campo próprio de formação profissional e os saberes curriculares das áreas específicas do seu trabalho docente; e de concepção pedagógica que baseiam os processos de ensino-aprendizagem.

Torna-se relevante para o professor, esse engajamento da teoria com a prática no trabalho junto aos alunos. É um processo no qual se descreve os conhecimentos e experiências debatidos em sala, suas hipóteses, seus procedimentos e os elementos de políticas educativas, além dos conhecimentos adquiridos na trajetória cotidiana da vida pessoal, social, cultural e escolar. Percebe-se nessa prática um entrelaçamento favorável ao aprendizado, no qual o docente não somente domina, mas impulsiona, motiva ao conhecimento dos significados. 
Os métodos pedagógicos entre professor e o aluno torna-se um aprendizado histórico real, são instrumentos que se interligam a linguagem e facilitam o processo de formação das pessoas. Assim, o professor e o estudante crescem juntos, pois a sociedade passa por diversas modificações, dentre essas o ensino-aprendizagem, que está conectado num processo amplo e cobra cada vez mais do indivíduo.

Nessa visão cada ser deve se adaptar, ser dinâmico, ativo, respeitar as diferenças e conhecimentos adquiridos no decorrer da vida individual ou em grupo. Com isso, a prática pedagógica tem papel fundamental no desenvolvimento intelectual do aluno, ele é o centro da aplicação metodológica na condução da aprendizagem. O professor necessita refletir sobre a questão:

Educar é intervir na capacidade de ser e de agir das pessoas. Para isso, são providas as mediações culturais, isto é, as ferramentas simbólicas e materiais, mediante um processo de comunicação. É disto que trata a Pedagogia: a mediação de saberes e modos de agir. (LIBÂNEO, 2006, p. 215)

Ao entender essas considerações, percebe-se a necessidade da interação entre os membros escolares, porque só poderão desfrutar, transformar, organizar e atender os interesses se trabalharem visando o coletivo, pois é disso que advém a aprendizagem e a verdadeira educação de qualidade social.

Assim as atividades que estimulam a autonomia, envolvem os alunos na organização, no planejamento e nas pesquisas para exercitar a capacidade de expressão e comunicação. Nesse contexto, os professores aplicam os conteúdos curriculares, visando adequá-los à necessidade da sua clientela, pois a educação é uma ação social que requer um processo de interação entre professor e aluno. Na conjuntura em que o ensino acontece, o trabalho pedagógico na práxis da sala de aula ou de outros espaços educacionais qualifica o educador como um ser epistemológico. Logo o saber ensinar e a competência docente, está intimamente relacionado à construção de uma autonomia para a ação atenta, refletida, crítica e ética.

Paulo Freire faz a seguinte colocação, acrescentando que: 
[...], o diálogo é uma exigência existencial. E, se ele é o encontro em que se solidarizam o refletir e o agir de seus sujeitos endereçados ao mundo a ser transformado e humanizado, não pode reduzir-se a um ato de depositar ideias de um sujeito no outro, nem tampouco tornar-se simples troca de ideias a serem consumidas pelos permutantes. (FREIRE, 2005, p. 91).

A escola hoje tem novas exigências educacionais e o professor enfrenta desafios, ao ter que abandonar velhas práticas e as metodologias ultrapassadas, pois não são mais suficientes para atender o sistema educacional brasileiro, a escola já tem um perfil contemporâneo de aprendizagem, que favorece os alunos a enfrentarem os desafios que a sociedade impõe. Para tanto é importante que se faça uma autoanalise, do que se pode fazer para implementar a prática pedagógica e superar os anseios diante da necessidade de mudança. Assim,

Aprender dentro da visão da pedagogia dos conteúdos, é desenvolver a capacidade de processar informações e lidar com os estímulos do ambiente, organizando os dados disponíveis da experiência. Em consequência, admite-se o princípio da aprendizagem significativa que supõe, como passo inicial, verificar aquilo que o aluno já sabe. $O$ professor precisa saber(compreender) o que os alunos dizem ou fazem, o aluno precisa saber compreender o que o professor procura dizer-lhes. (LIBÂNEO, 2006, p. 42)

E diante dessas exigências, com objetivo de novas perspectivas na área da educação, para a transformação metodológica da prática do professor em tomada de decisão na sala de aula e em outros espaços educativos, leva-os a produzirem saberes com metodologias inovadoras. Cabe a ele dinamizar, adequando a sua criativamente, na prática de sala de aula, no contexto de interação com os alunos, e em diferentes atividades metodológicas. Desse modo, a práxis pedagógica incentiva o educador a ser uma pessoa hermenêutica, levando-os a serem mediadores de saberes, para uma prática dinâmica, reflexiva e transformadora.

\subsection{ENSINO-APRENDIZAGEM CONTEMPORÂNEO}

A escola no século XXI vem acompanhar as mudanças sociais, com a implementação das novas tecnologias que influencia as culturas e as relações da sociedade em ritmo acelerado, e as informações são atualizadas em frações de segundos. Com isso, 
houve exigências educacionais, a escola de hoje não segue e nem deve seguir as mesmas metodologias ou práticas de ensino de tempos anteriores, precisam orientar e enfrentar novos desafios.

As velhas práticas, as ferramentas ultrapassadas e as metodologias retrógradas já não suprem as necessidades da educação atual. É necessário levar em consideração que as informações se tornaram mais rápidas e acessíveis, tornando os estudantes mais autônomos e conectados nas novas tecnologias e mídias sociais, por estarem revolucionando a forma de ensinar e aprender.

Isso tudo requer uma escola com um perfil moderno de aprendizado, que auxilie o aluno a vencer todos os desafios que a sociedade atribui. Nessa conjuntura, é necessário ressaltar a importância da capacitação contínua do professor no intuito de inovar e disponibilizar aperfeiçoamento nas práticas pedagógicas e manter sempre a atualização daquilo que o próprio sistema educacional cobra, em consonância com a sociedade.

No Brasil ao longo dos anos são implementadas novas propostas pedagógicas, no intuito de disponibilizar melhorias no sistema educacional. Então, a educação brasileira em todos os níveis, vem sofrendo transformações com ações educativas que permitem conhecer determinados sistemas.

Trata-se de uma pedagogia que leva em conta os determinantes sociais e que propicia a crítica dos mecanismos e imposições resultantes da organização da sociedade em classes sociais antagônicas; ao mesmo tempo, é uma pedagogia que vai buscar, no interior da escola, respostas pedagógico-didáticas que permitem o exercício dessa crítica, a partir das próprias determinações sociais das situações pedagógicas concretas. (LIBÂNEO 2006, p. 12).

O exemplo recente de reformas foi à proposta "Educação para todos" em 2001, como salvacionista da educação, para a melhoria da qualidade da aprendizagem, como a condição do desenvolvimento, redução da pobreza, empregabilidade e melhor qualidade de vida. 
As visíveis transformações que vem ocorrendo na sociedade contemporânea com rápidas modificações refletem no sistema educacional, pois a educação é um fenômeno social que contribui, influencia e possibilita um novo paradigma social de ensino-aprendizagem. A educação deve estar voltada para o desenvolvimento das competências e habilidades essenciais para os alunos, e nesse contexto o professor deve ter uma postura peculiar que direcione o processo educacional. As novas tecnologias prendem a atenção, visto que o computador, a televisão, o data show a internet, telefones celulares e etc., favorecem a construção de conhecimentos e facilita a cognição, criando um ambiente muito estimulante de ensino aprendizagem.

Ao se tratar do desenvolvimento de competências e habilidades, o professor precisa conhecer estratégias de ensino, buscar a ressignificação das ações praticadas no tempo e no espaço do ambiente escolar de maneira a garantir que o anseio do aluno não seja contrariado. Dessa forma segundo Libâneo (2006, p. 78), "O professor precisa de uma teoria, que explicite a direção pretendida para a tarefa educativa de humanização do homem, extraída de uma concepção de educação enquanto prática social transformadora".

A educação é alicerçada por seres capazes de criar e recriar, ela é desvendada a cada passo, entre professores, estudantes e todos os seguimentos da sociedade, por isso é um processo contínuo. A partir da escola o ser humano organiza o seu universo de ideias e cede a novas possibilidades do conhecimento universal, desde que seguindo os processos pedagógicos de ensino.

$\mathrm{Na}$ escola contemporânea o desafio para muitos professores é transformar as tecnologias em aliada da educação, hoje é preciso criar estratégias inovadoras de ensino, mesmo que usando os recursos tradicionais e nelas sempre está presente os livros, lápis, caneta e papel. E quando a escola dispõe das novas tecnologias, principalmente as multimídias é necessário se valer da interatividade.

Mesmo assim, as inovações podem e precisam conter instrumentos tecnológicos, como é previsto na Base Nacional Comum Curricular (BNCC). São diversos os meios de introduzir nas atividades pedagógicas essas práticas, tais como: nas produções, 
nas propostas de leitura dinâmica, nas aplicações de avaliações e simulados e na recorrente apreciação de histórias e filmes educativos. Nesse ambiente dinâmico, o uso didático do celular por exemplo, pode auxiliar e motivar os estudantes no processo de ensino-aprendizagem.

[...] o professor agiria como estimulador da aprendizagem cuja iniciativa principal caberia aos próprios alunos. Tal aprendizagem seria decorrência espontânea do ambiente estimulante e da relação viva que se estabeleceria entre os alunos e entre estes e o professor, para tanto, cada professor teria que trabalhar com pequenos grupos de alunos, sem o que a relação interpessoal, essência da atividade educativa, ficaria dificultada; e num ambiente estimulante, portanto, dotado de materiais didáticos ricos, biblioteca de classe etc. (SAVIANI, 1995, p. 20)

Dentro desse contexto o professor é o mediador do conhecimento, proporcionando situações e experiências significativas aos alunos que se tornam sujeitos da própria formação. É preciso envolver toda a sociedade para gerar uma educação democrática. Mas para o desenvolvimento de uma sociedade de informação de igualdade é preciso que haja realmente políticas de acesso à informação direcionada a todos, para o progresso e transformação constantemente da humanidade. Portanto a educação precisa de um novo sistema de ensino, que só será possível quando toda a sociedade se envolver.

\section{CONSIDERAÇÕES FINAIS}

O imaginário social surge em um contexto sócio-histórico-cultural e influencia decisivamente as relações sociais e é determinante para o ensino-aprendizagem, com significação e simbologia imaginária. Mas sabemos que o processo educativo demanda e muita atualização, as práticas pedagógicas são reinventadas e criando novas maneiras de ensinar e aprender, o professor necessita se atualizar sempre. A importância de uma educação interdisciplinar e multidisciplinar que atenda a nova realidade educacional de globalização de saberes.

O processo educativo necessita de muita atualização, os métodos estão em constante evolução e melhorando as práticas pedagógica e nova maneira de ensinar e aprender é necessário o empenho de todos para tornar a educação excelente nesse país. 
O professor precisa ter uma mente aberta e deve se aliar as transformações tecnológicas de forma a beneficiar suas aulas, aprimorando as práticas metodológicas que promovam o processo de ensino-aprendizagem.

O novo paradigma das relações sociais está atrelado pela tecnologia, independentemente de qualquer ambiente socioeconômico e cultural, os alunos criam estruturas mentais e cognitivas que agrupam e se ampliam a partir das TICs. O professor, por sua vez, constitui um novo método de transmissão de ensino aprendizagem e, simultaneamente, de controle desse conceito, pois a forma de avaliar os alunos precisam também ser diferenciadas e adaptadas ao novo padrão de ensino.

Dessa forma a educação deve ir além de um conjunto de procedimentos, normas e técnicas, é um processo construtivo e permanente. A escola necessita de inovações, mas é preciso comprometimento de todos com as transformações sociais tendo em vista o bem-estar de toda a sociedade.

\section{REFERÊNCIAS}

CASTORIADIS, Cornelius. As encruzilhadas do labirinto VI-figuras do pensável. Rio de Janeiro: Civilização Brasileira, 2004.

FREIRE, P. Pedagogia do Oprimido. Rio de Janeiro: Paz e Terra, 2005.

LIBÂNEO, José Carlos - Democratização da escola pública - a pedagogia críticosocial dos conteúdos, 2006, $21^{\circ}$ edição.

PESAVENTO, Sandra. Em busca de outra história: imaginando o imaginário. Revista Brasileira de História, São Paulo, v. 15, no 29, 1995.

POSTIC, Marcel. O imaginário na relação pedagógica. Rio de Janeiro: Jorge Zahar. 1993.

SAVIANI, Demerval. Escola e Democracia. Campinas: Autores Associados, 1995. 
VIGOTSKY, L S. La imaginación y el arte em la infância. (Ensayo psicológico). 3. ed. Madrid, Espanha: Akal., 1996.

Enviado: Setembro, 2020.

Aprovado: Outubro, 2020. 